\title{
Study on temperature drop of molten steel during converter tapping
}

\author{
Zhiyong Fan ${ }^{1, a}$, Wei Xiong, b , Yifei Huang ${ }^{1, c}$ \\ ${ }^{1}$ Key Laboratory for Ferrous Metallurgy and Resources Utilization of Ministry of Education, Wuhan \\ University of Science and Technology, Wuhan 430081, China

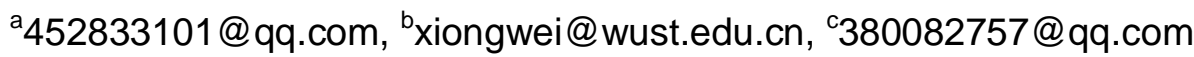

\begin{abstract}
Keywords: converter; tapping; molten steel temperature; mathematical model
Abstract. Molten steel temperature in ladle after converter tapping has a strong effect on yield rate of alloy, dosage of deoxidizing agent and production efficiency. A mathematical model taking ladle thermal state into account was established for temperature prediction of molten steel during tapping and it was compared with the measured values. The results obtained show that the heat loss from molten steel stream to ambient is almost negligible due to less distance from tapping hole to ladle hole, and the total percentage of heat losses from ladle lining and top surface of steel bath is above $60 \%$. The higher tapping temperature is, and the greater decalescence of ladle lining is , the greater temperature drop is. When tapping quantity is reduced by 20ton, molten steel temperature after tapping is reduced by about $6^{\circ} \mathrm{C}$ additionally.
\end{abstract}

\section{Introduction}

With demanding of high quality and low price steel for market, steel suppliers are striving for improving steelmaking processes and equipment to enhance production competitiveness and further reduce production cost as well as improve quality of production [1-3]. It plays an important role for precise estimation and control of molten steel temperature in modern steel production studied emphatically at home and abroad, but the calculated value is noted to be unsatisfactory or be merely suitable for some certain plants $[4,5]$.

A mathematical model taking ladle thermal state into account was established for temperature prediction of molten steel during tapping based on metallurgical thermodynamics, heat transfer and thermal balance, and influence factors of molten steel temperature were analyzed. Calculating temperature drop of molten steel in tapping process by simulating as an object of study, this paper establishes theoretical foundation for controlling temperature of ladle lining and molten steel during converter tapping in future.

\section{Mathematical Model}

Temperature drop of molten steel during converter tapping can be classified as: (1) Heat loss of molten steel stream from tapping hole to ladle hole; (2) Heat loss of molten steel to refractory ling and ambient at the top surface of steel bath; (3) Heat loss of additions. Fig. 1 shows the model about the first two parts of temperature drop of molten steel.

Charging and tapping was ongoing simultaneously. The weight of molten steel in ladle was increased continuously, and the level of steel bath rose rapidly. The heat loss from top surface of steel bath took place through natural convection and radiation, and a part of heat was absorbed by ladle lining in contact with molten steel by heat conduction [6,7]. Adding ferroalloys, deoxidizing agent and flux contributed to the heat loss to molten steel.

The temperature variation of molten steel in ladle was simulated based on following assumptions:

(1) The radial heat flux had only been taken into account because the thickness of ladle wall is much smaller than its height.

(2) The axial heat flux had only been taken into account because the thickness of ladle bottom is 
much smaller than its diameter.

(3) The molten steel bath was homogenized with average bulk temperature of the molten steel in ladle.

(4) The surface temperature of slag layer and temperature of molten steel were approximately equal due to sufficient stirring from molten steel stream into ladle during tapping.

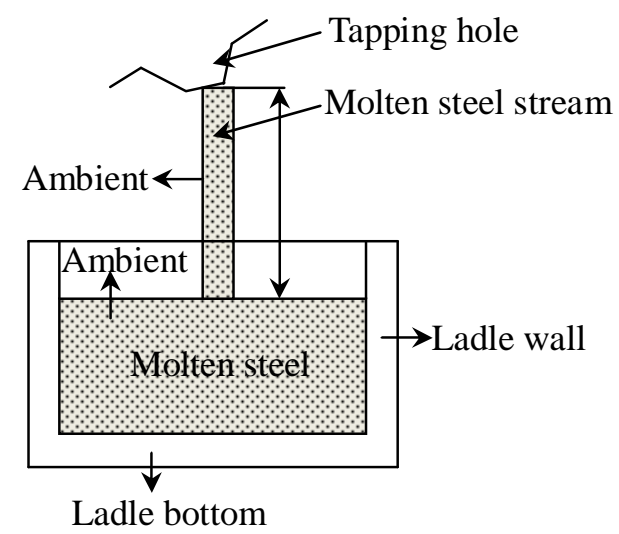

Fig. 1 Schematic of heat loss from molten steel during tapping

The level of top surface of steel bath rose slowly with accumulation of molten steel in ladle during tapping. The inner surface of ladle wall in contact with molten steel was divided into $N$ vertical equal segments in terms of tapping time along with height of ladle for calculating heat flux through ladle walls and its relevant temperature distribution. It is shown in Fig.2. There is different temperature at inner surface of each vertical segment upon the whole height of ladle, and midpoint temperature of each vertical cross-section represented the temperature of the ladle walls corresponding to the direction of radius. The heat transfer along with direction of height was ignored, and temperature distribution of the wall lining was the average value of each segment.

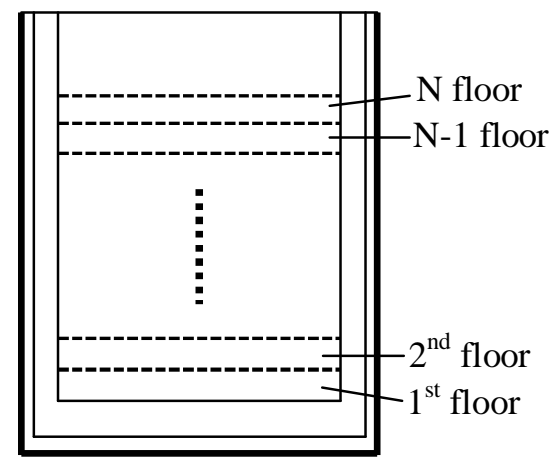

Fig. 2 Division of ladle wall during tapping

The equations of heat conduction were mentioned in Eq. (1) and Eq. (2).

$$
\begin{aligned}
& \frac{\partial T_{\mathrm{w}}}{\partial \tau}=\frac{1}{\rho_{\mathrm{w}} \cdot C_{\mathrm{pw}}(T)}\left[\frac{1}{r} \frac{1}{\partial r}\left(\lambda_{\mathrm{w}}(T) \cdot r \frac{\partial T_{\mathrm{w}}}{\partial r}\right)\right] \\
& \frac{\partial T_{\mathrm{b}}}{\partial \tau}=\frac{1}{\rho_{\mathrm{b}} \cdot C_{\mathrm{pb}}(T)}\left[\frac{1}{\partial z}\left(\lambda_{\mathrm{b}}(T) \cdot \frac{\partial T_{\mathrm{b}}}{\partial z}\right)\right]
\end{aligned}
$$

The boundary and initial conditions were described in Eq. (3) and Eq. (4). 


$$
\begin{aligned}
& \left.\begin{array}{l}
r=r_{\text {inner }}, q_{\mathrm{w}-\text { in }}(\tau)=\alpha_{\mathrm{w}-\text { in }}\left(T_{\mathrm{st}}(\tau)-T_{\mathrm{w}\left(r_{\text {imerer }}\right)}\right) \\
r=r_{\text {outer }}, q_{\mathrm{w}-\text { out }}=\alpha_{\mathrm{w} \text {-out }}\left(T_{\mathrm{w}\left(r_{\text {outer }}\right)}-T_{\mathrm{a}}\right) \\
\tau=0, T_{\mathrm{w}}=T_{\mathrm{w}}(r)
\end{array}\right\} . \\
& z=\mathrm{z}_{\text {inner }}, q_{\mathrm{b} \text {-in }}(\tau)=\alpha_{\mathrm{b} \text {-in }}\left(T_{\mathrm{st}}(\tau)-T_{\mathrm{b}\left(z_{\text {inner }}\right)}\right) \\
& z=z_{\text {outer }}, q_{\mathrm{b} \text {-out }}=\alpha_{\mathrm{b} \text {-out }}\left(T_{\mathrm{b}\left(z_{\text {outer }}\right)}-T_{\mathrm{a}}\right) \\
& \tau=0, T_{\mathrm{b}}=T_{\mathrm{b}}(z)
\end{aligned}
$$

The energy balance equation of molten steel during tapping was described in Eq. (5).

$$
M_{\mathrm{st}}(\tau) C_{\mathrm{pst}} \frac{d T_{\mathrm{st}}}{d \tau}=C_{\mathrm{pst}} \rho_{s t} \pi r_{0}^{2} v_{\mathrm{in}}\left[T_{\mathrm{in}}-T_{\mathrm{st}}(\tau)\right]+q_{\mathrm{w}-\mathrm{n}}(\tau) A_{\mathrm{w}}(\tau)+q_{\mathrm{b}-\mathrm{in}}(\tau) A_{\mathrm{b}}+q_{\mathrm{sl}}(\tau) A_{\mathrm{sl}}+Q_{\mathrm{alloy}}(\tau) .
$$

The Eq. (1), Eq. (2) and Eq. (5) were solved simultaneously for molten steel, walls and bottoms by the finite difference method at each second. Here $Q_{\text {alloy }}(\tau)$ was heat effect from alloys addition, deoxidizing agent and flux. $q_{\mathrm{sl}}(\tau)$ was the heat flux of top surface of steel bath at time $\tau$, and it was obtained by the following Eq. (6).

$$
q_{\mathrm{sl}}(\tau)=-\varepsilon_{\mathrm{sl}} \sigma\left[\left(T_{\mathrm{st}}(\tau)+273\right)^{4}-\left(T_{\mathrm{a}}+273\right)^{4}\right]-\alpha_{\mathrm{sl}}\left[T_{\mathrm{st}}(\tau)-T_{\mathrm{a}}\right] .
$$

\section{Results and Discussion}

Fig.3 shows the errors of calculated against measured temperatures at tapping-out. The average error within $10^{\circ} \mathrm{C}$ is by $87.5 \%$.

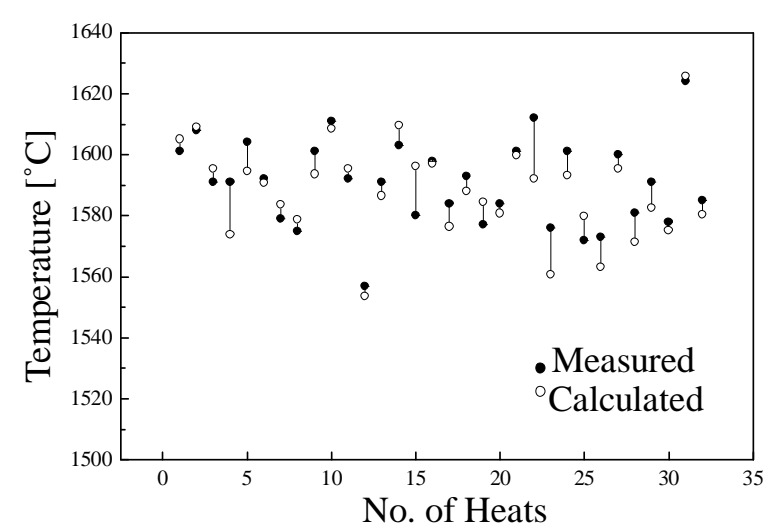

Fig. 3 Comparison of molten steel temperature between calculated and measured values

The heat losses of molten steel during tapping were listed in Table 1. The heat loss of molten steel stream can almost be ignored owing to shorter distance from tapping hole to ladle hole. The total percentage of heat losses from ladle lining and top surface of steel bath was above $60 \%$. The heat loss of ferroalloy and flux added was more than $35 \%$.

Table 1 Analysis of heat losses from molten steel

\begin{tabular}{cc}
\hline & Percentage[\%] \\
\hline Molten steel stream & 0.44 \\
Top surface of steel bath & 5.25 \\
Ladle lining & 58.48 \\
Alloy and flux & 35.83 \\
\hline
\end{tabular}


Fig.4(a) shows the temperature variation of molten steel with time for different tapping quantity. When tapping quantity was reduced by 20t, molten steel temperature was reduced by about $6^{\circ} \mathrm{C}$ additionally, and it was about $0.3^{\circ} \mathrm{C}$ per ton.

Fig.4(b) shows the temperature variation of molten steel with time for different tapping temperature. The temperature drop of $34^{\circ} \mathrm{C}$ was noticed for the tapping temperature of $1630^{\circ} \mathrm{C}$ as compared to $41^{\circ} \mathrm{C}$ for tapping temperature of $1655^{\circ} \mathrm{C}$ and $48^{\circ} \mathrm{C}$ for tapping temperature of $1680^{\circ} \mathrm{C}$. The temperature drop was further reduced to $27^{\circ} \mathrm{C}$ for tapping temperature of $1605^{\circ} \mathrm{C}$. Thus, the maximum temperature drop was observed for $1680^{\circ} \mathrm{C}$ and minimum for $1605^{\circ} \mathrm{C}$. This was due to the high initial rate of heat transfer for tapping temperature of $1680^{\circ} \mathrm{C}$. It was indicated that the higher the tapping temperature was, and the greater decalescence with ladle was, the greater the temperature drop was.

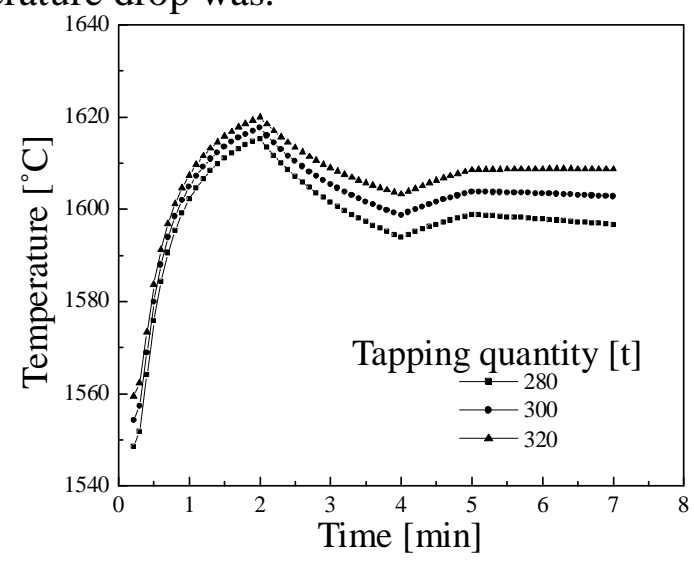

(a)

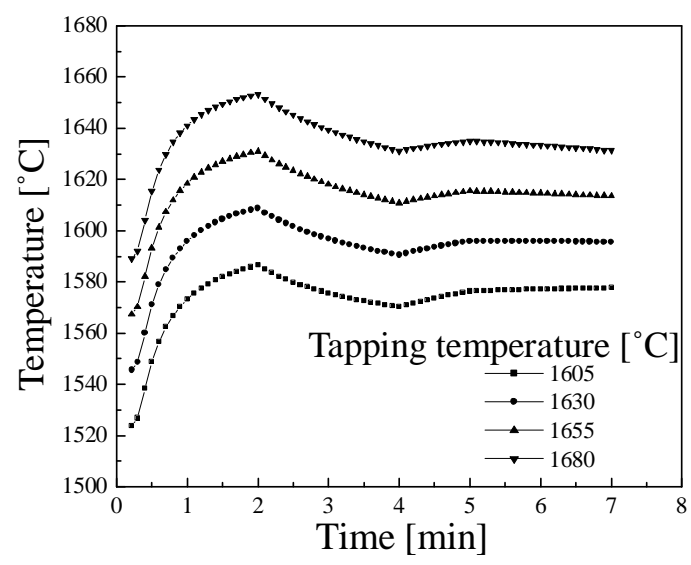

(b)

Fig. 4 Effect of tapping factors on temperature drop of molten steel

\section{Conclusions}

The results obtained from the simulation in this study are summarized as follows:

(1) A mathematical model taking ladle thermal state into account was established for temperature prediction of molten steel during tapping based on metallurgical thermodynamics, heat transfer and thermal balance. The model was validated with data collected from plant and the comparison between calculated and measured values show that the values having average error within $\pm 10^{\circ} \mathrm{C}$ is by $87.5 \%$. It was verified that the model was available for guiding the practical production.

(2) Ladle thermal state has more impact on molten steel temperature, the total percentage of heat losses from ladle lining and top surface of steel bath is above $60 \%$.

(3) The higher tapping temperature is, and the greater decalescence of ladle lining is, the greater temperature drop is. Tapping quantity has greater influence on temperature drop of molten steel during tapping. When the tapping quantity is reduced by 20 ton, molten steel temperature after tapping is decreased by about $6^{\circ} \mathrm{C}$ additionally, and it is about $0.3^{\circ} \mathrm{C}$ per ton. The temperature drop rate is decreased with the increase in tapping time.

\section{References}

[1] A. Tripathi, J. K. Saha and J. B. Singh: ISIJ Int, Vol. 52 (2012), p. 1594

[2] N. K. Nath, K. Mandal and A. K. Singh: Ironmaking and Steelmaking, Vol. 33(2006), p. 141

[3] D. Y. Li and Y. R. Wang: Iron \& Steel, Vol. 31(1996), p. 17 
[4] M. L, Wang, L, Liu and P. He: Iron \& Steel, Vol. 37(2002), p. 14

[5] Q. Yang and L. Liu: Steelmaking, Vol. 15(1999), p. 32

[6] O. Volkova and D. Janke: ISIJ Int, Vol. 43(2003), p.1185

[7] T. P. Fredman, J. R. Torrkulla and H. Saxen: Metal.Mater. Trans. B, Vol. 30(1999), p. 323 